\title{
ANAEROBIC RESPIRATION OF CACTI ${ }^{1}$
}

Felix G. Gustafson

(Received for publication April 9, 1932)

The writer's studies of anaerobic respiration of several different varieties of fruits and such underground parts as tubers and rhizomes have now been extended to the fleshy structures of cacti. This work was done at the Desert Laboratory of the Carnegie Institution of Washington at Tucson, Arizona, during the winter months of October to January. Although the climate in Tucson is rather mild as winters go, yet it was by no means warm. There were several periods when for one night or several nights in succession the temperature was below freezing. For the greater part of the time there was not much growth of any kind and certainly not in any of the cacti used in these experiments.

The temperature of the bath in which the experiments were conducted gradually rose during a period of three and a half months from $25^{\circ}$ to $25.5^{\circ}$ $\mathrm{C}$., but during an individual experiment, lasting usually a week, the change was so slight that it could not be detected. For respiration chambers largemouthed pickle jars were used. Otherwise the experiments were conducted as in the past (I). In order to establish an equilibrium, the plants (kept in the dark) were in the respiration chambers, through which air was drawn, usually for about 20 hours before the collection of $\mathrm{CO}_{2}$ was commenced.

Six species of cacti and the leaves from two species of thin-leaved plants were used. The leaves were used to get a comparison between fleshy plants and thin-leaved structures from the same habitat and under identical conditions. The plants used were: Carnegiea gigantea, Ferocactus wislizeni, Neomanimillaria microcarpa, Echinocereus fendleri, Opuntia engelmannii, $O$. versicolor, and the leaves of Verbena ciliata and Encelia farinosa. The cacti ranged in compactness from the nearly spherical Ferocactus to the flat Opuntia engelmannii and the long and cylindrical growth of Opuntia versicolor. (The names as here used are those given by Britton and Rose, "The Cactaceae.")

To eliminate the activity of bacteria or fungi all plants used were first washed free from soil and other foreign matter and were always healthy and uninjured, except where joints were broken off or roots cut off, and in one experiment with Ferocactus wislizeni in which a fungus infection developed. Sometimes these injured surfaces healed before the plants were introduced into the respiration chambers, or they were coated with vaselin or grafting wax, although in some experiments joints with fresh cuts were placed in

${ }^{1}$ Paper from the Department of Botany of the University of Michigan, No. 377. 
the chambers. When the plants were taken out of the chambers at the end of the experiments they were always examined for fungus or bacterial action, but only in the instance mentioned above were evidences of infection noted in the plants that had been in nitrogen. In a few instances the plants in air had fine wefts of fungus on the roots. It seems to the writer that bacterial and fungal responsibility for the $\mathrm{CO}_{2}$ production under the experimental conditions can very definitely be excluded.

\section{Carnegiea gigantea}

More experiments were conducted with this plant than with any other, partly because it is typical of this region and partly because small specimens were easily available. Dr. Shreve had on hand a large number of Carnegiea gigantea plants, grown from seeds, that were seven years old and these were very satisfactory for the work. Larger plants were easily obtained from the mountains. In all, seven experiments with controls were conducted with the giant cactus or "Sahuaro," as it is more commonly called in Arizona.

To get some idea of the normal respiration of cacti, over an extended period of time, an introductory experiment was conducted in which two different sizes of Carnegiea gigantea were used. Each group was run in duplicate. The plants grown in the greenhouse were used and they ranged in size from 3 to 4 inches in height. The larger plants (about 6 inches) were collected in the field.

From this introductory experiment (text fig. I) it will be seen that the

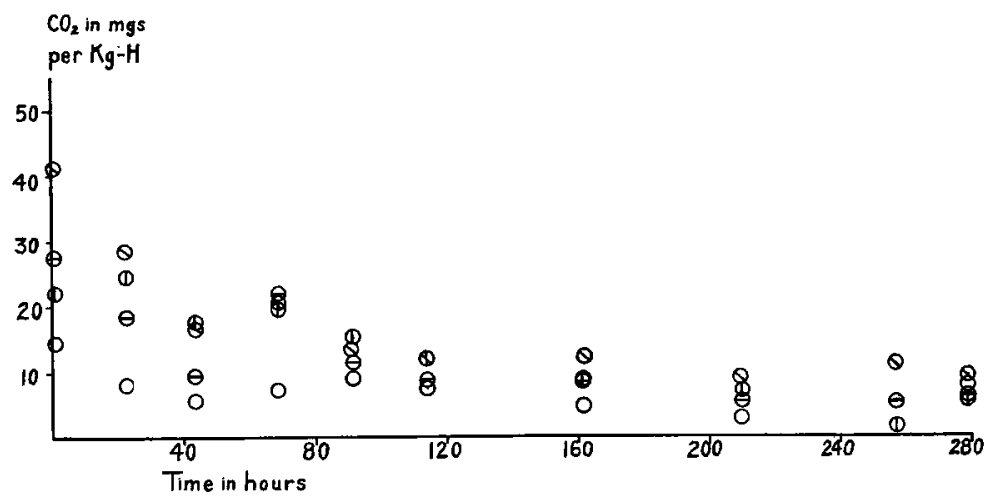

TeXT Fig. I. Respiration in air of plants of Carnegiea gigantea of two different sizes. The plain circles and the circles with the horizontal line through them represent two experiments with 7 -year-old plants 3 to 4 inches in height. Three plants were used in each experiment. The other two experiments were conducted with older plants, 6 inches in height. Each circle represents the average of two collections. This is true for all of the experiments cited in this paper. The plants represented by the plain circles and the circles with the perpendicular line through them were taken out of the chamber $23 \mathrm{I}$ hours after the first collection was made, or 275 hours after the plants were put in the dark chambers, and placed in the sun out of doors for 7 hours. They were returned to the chamber and collections made next day as before. 
respiration of cacti is very low when compared with other plants. In oniy one collection was the amount of $\mathrm{CO}_{2}$ produced more than 30 mgs. per kilogram hour. This is low even when compared with ripe fruits. Collections were made in this experiment for a period of 280 hours, and the plants were in darkness for about 320 hours, yet the respiration was fairly well sustained. In fact there was only a slight decrease after the first hundred hours. To find out whether organic substances were running low the plants from one container from each group were taken out after having been in darkness for 275 hours and placed in the sun for 7 hours. They were then returned to the containers and measurements made the following day as before. The small plants showed an increase for the two days that followed, while the large plant did not. In fact its $\mathrm{CO}_{2}$ production was less the day after it had been in the sun than it had been before.

In experiment 8 (text fig. 2) 3 seven-year-old plants were used. They
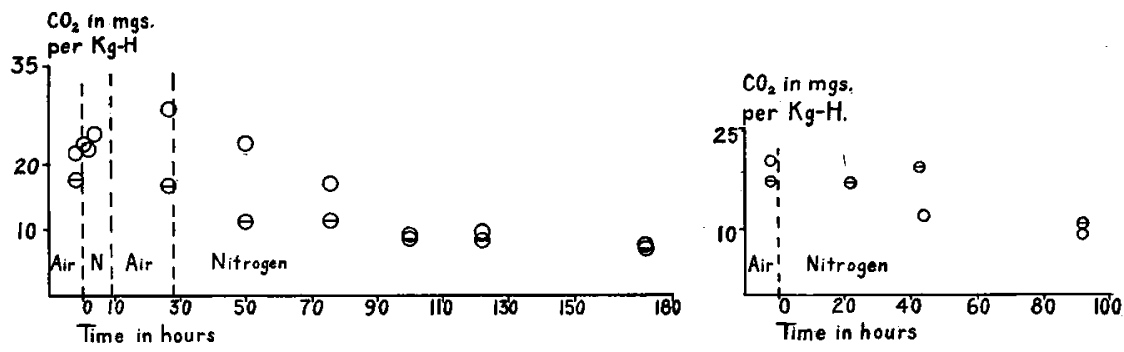

Text FIgs. 2 And 3. FIg. 2 (left). Respiration of 7-year-old Carnegiea gigantea plants. Three plants were used in each respiration chamber. The plain circles represent the plants in nitrogen in all experiments except those in text figure I. Fig. 3 (right). Respiration of Carnegiea gigantea plants, 8 inches tall.

varied in size from $2 \frac{\mathrm{T}}{2}$ to $4 \frac{\mathrm{T}}{2}$ inches in height. They had been in nitrogen only $91 / 2$ hours when air.was again introduced because of a leak in the valve supplying the nitrogen from the tank. The next day nitrogen was again introduced and the plants remained in nitrogen continuously for I42 hours. The plants in nitrogen maintained a higher rate of $\mathrm{CO}_{2}$ production for two days than did the plants in air. After that the rate was practically the same for control and experimental plants. When the plants were taken out of the respiration chamber the smallest plant in the nitrogen showed a slight browning on several ribs near the apex. The other two seemed to be in good condition. After some days the plants were put in soil and kept in the greenhouse. The two smaller plants developed blackening at the apex after some time and were discarded. The third plant was still in good condition two and a half months after the experiment was ended. The blackening noticed may not have been due to injury after all, as other plants from the same lot growing in the greenhouse have also developed black apices, without having been in nitrogen. 
In experiment 42 , which was conducted in January, Carnegiea gigantea was also used. These plants were 8 inches tall and 4 inches in diameter. The respiration in these plants was very low (text fig. 3 ); the highest only 20 milligrams per kilogram per hour. It is to be noted that the plants in this experiment had been exposed to low temperature for several weeks before they were used. This may to some extent account for the small amount of $\mathrm{CO}_{2}$ produced in comparison with the other two experiments cited above, which were conducted in October, when the temperature was much higher. In this experiment there was no great difference in the rate of the control and the experimental plant, except for one day. The plant which had been in nitrogen showed a patch of yellow-gray color on one side near the apex. On cutting into the plant it was found that the chlorophyll had partly disintegrated, becoming yellow-brown (instead of the usual bright green). The chlorophyll disintegration extended into the plant for only 2 or 3 millimeters.

Two attempts were made to use plants over a foot tall, but the containers could not be maintained air tight for any length of time. One plant was in an atmosphere of nitrogen for nearly two days. During this time the $\mathrm{CO}_{2}$ production was actually much higher than it had been while in air.

All experiments with Carnegiea gigantea show that this plant is capable of living in an atmosphere free from oxygen for several days with only superficial injuries and some plants were not at all injured. During this time they maintained a rate of respiration which did not differ very much from the control. In some it was a little lower while in others a little higher than the control.

\section{Ferocactus Wislizeni}

This plant is an interesting subject for experiments in anaerobic respiration. In outline it is almost a perfect sphere with ridges running perpendicularly. This supplies a relatively small surface for a large volume and therefore the gas exchange might also be expected to be slow, with high content of $\mathrm{CO}_{2}$ and low content of oxygen, at least in the central part of the plant. If the interior is normally low in oxygen content, these plants would be expected to suffer less injury and respire more, when in total absence of oxygen, than plants which normally have high oxygen content in their interior.

Four experiments, each one with a control, were run with this plant. The rate of respiration, either aerobic or anaerobic, was very low; in two of the experiments the $\mathrm{CO}_{2}$ production was less than 20 mgs. per $\mathrm{Kg}-\mathrm{H}$. The others were all less than $40 \mathrm{mgs}$. per $\mathrm{Kg}-\mathrm{H}$. except in one reading, where it was 42.

In experiment Io and its control the plants weighed $38 \mathrm{I} .8$ and $326.9 \mathrm{~g}$., respectively, and measured about 4 inches in diameter, not including spines. As shown by text figure 4 the plant in nitrogen respired more than the control at the beginning of the experiment. The next day, 20-24 hours 
after nitrogen introduction, the experimental plant respired only 60 percent as much as it did in air the preceding day, and the control had decreased only a few percent. Next day there was only a slight decrease. At the end of 48 hours the nitrogen was replaced by air, and the plant remained in it for 94 hours. At the end of the aerobic period two collections were made from each one of the plant chambers. It was found that the two plants respired approximately the same at this time. The air was replaced by nitrogen and the next day the plant in nitrogen showed an increase over the plant in air. When the plants were examined at the end of the experiment.
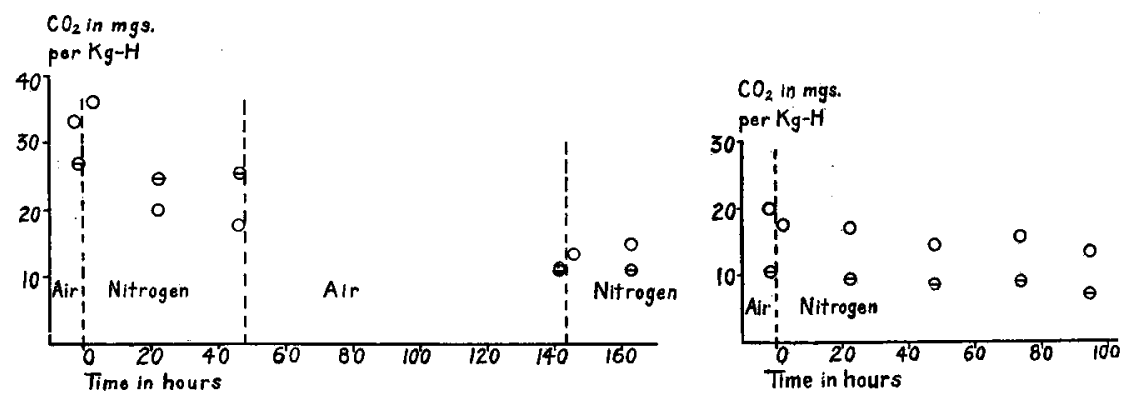

TExt Figs. 4 AND 5. FIG. 4 (left). Respiration of Ferocactus wislizeni plants, about 4 inches in diameter. FIG. 5 (right). Respiration of Ferocactus wislizeni plants, 4 inches in diameter. Note the very low rate of respiration.

eight days after they were placed in the containers in the dark, they were both found to be in perfect condition. They were planted in soil and placed in the green house. Two months later when again examined they were found to be in perfect condition. No new roots had been formed in either one, but that was not to be expected at this time of the year.

The other experiments showed no appreciable decrease in the respiration at the end of 24 hours in nitrogen. In experiment I5 (text fig. 5) there was a slight decrease immediately after placing the plants in nitrogen, but after that the decrease in $\mathrm{CO}_{2}$ production was approximately the same as that in the control plant. The control plant respired considerably less than the plant in nitrogen throughout the experiment. These plants were of approximately the same size as the plants in experiment 9. At the end of the experiment both plants were in perfect condition and when examined six weeks later they were found to be healthy and uninjured in every respect.

One of the two remaining experiments was conducted with small plants and the other with plants of the same size as in the cited experiments. In one of these the respiratory rate increased somewhat after the first day in nitrogen and this higher rate was maintained throughout the experiment. At the time this behavior was very puzzling but it later developed that the plants were infected with a fungus. This experiment should therefore be discarded in summarizing the results with Ferocactus wislizeni. In the 
fourth experiment, in which small plants were used, the rate gradually fell, but nearly the same in the control and the experimental plants. From these four experiments it seems certain that Ferocactus wislizeni is capable of carrying on anaerobic respiration for a considerable time with no injury to the plants.

\section{NEOMAM MILLARIA MICROCARPA}

This plant is rather small, usually about one and a half to two inches in diameter and from two to four inches tall, with small tubercles all over the surface. This plant therefore has a much larger surface per unit volume than does Ferocactus wislizeni.

Three experiments with controls were performed with this species. In all experiments several plants were used in each respiration chamber, because the individual plants were so small.

Experiment $\mathrm{I} 3$ with its control is typical and it is here illustrated by text figure 6. Four plants slightly different in size were used in each jar. Similar plants were selected for the two chambers. All plants were collected on the same hillside, a few days before they were used in the experiment. This
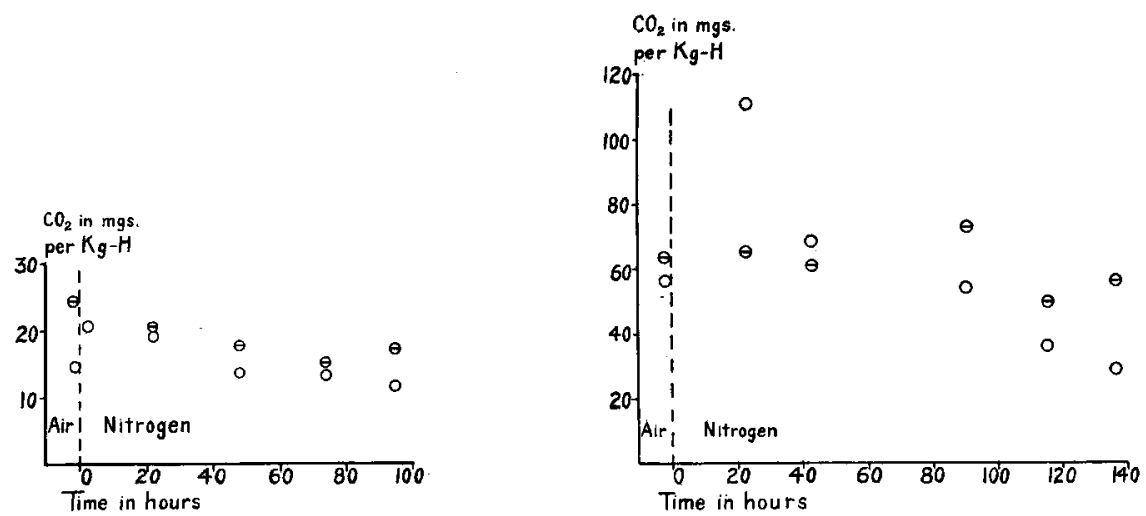

TeXt Figs. 6 AND 7. FIG. 6 (left). Respiration of Neomammillaria microcarpa plants. Four plants were used in each respiration chamber. FIG. 7 (right). Respiration of Opuntia versicolor joints. About 15 joints were used in each jar. Most of the joints were quite plump and short.

procedure was followed in all the experiments with Neomammillaria microcarpa.

It will be noticed that the plants in air respired considerably more at the beginning than the plants which were put into nitrogen in spite of the careful selection of similar plants.

During the first 24 hours the plants in nitrogen respired more than they had done when in air, but after that the rate fell below the original, though not as much as in the control. At the completion of the experiment the plants appeared normal except that the chlorophyll was of a brownish-green 
cast, and after some weeks the chlorophyll had disappeared entirely. To the touch they felt a little softer than the control plants. Microscopic examination of thin sections showed no definite difference between the control and the experimental plants. Six weeks after the plants were removed from the respiration chamber the three plants saved were again examined. They had been planted in sand in the meantime. One plant was dead. The other two plants showed a very interesting development. The tubercles which had shown the disintegration of chlorophyll were in many instances ready to slough off the outer layer and underneath this white and dry layer the tissue was of a bright green color showing active growth and development of new chlorenchyma tissue.

The other two experiments were in the main like the one described in detail. One of them showed a greater drop in nitrogen than the experiment cited. The plants were saved in only one experiment and after two months one very small one was dead, while the other four were alive and the outer injured layer of the tubercles was sloughing off and new chlorenchyma tissue had developed underneath.

On the whole Neomammillaria microcarpa showed a greater decrease in respiration when oxygen was excluded than did Ferocactus zoislizeni. It was also injured superficially and perhaps internally to a greater extent. Only the smallest plants, however, were injured beyond the surface layer, i.e., the chlorophyll-bearing layer, extending for two to three mm. below the surface.

\section{OPUNTIA VERSICOLOR}

Opuntia versicolor and $O$. engelmannii were both used to make complete the survey of the more common cacti found around Tucson.

Opuntia versicolor which has previously been used in several investigations on respiration is a profusely branched form, with cylindrical joints. The end joints are three-quarters of an inch to an inch in diameter. Joints separate very easily from one another and do not have to be cut apart, as a slight wrenching will separate them. Terminal joints were used in the two experiments conducted with this plant. Whether the terminal joints used were last year's growth or older cannot be stated, as not all apices will produce new joints every year. Material used in both experiments was obtained from the same large plant. Opposite or otherwise similarly situated joints were broken off and each one put in a separate lot. In this way the experimental joints and the control joints were as similar as was possible to get them.

In one of these experiments there was a very large increase in respiration immediately after the nitrogen was introduced. This increase lasted at least more than 24 hours. According to Richards (2) the $\mathrm{CO}_{2}$ production decreased to about half a few hours after the joints were put in nitrogen, when the temperature was maintained at $2 \mathrm{I}^{\circ} \mathrm{C}$., while at $35^{\circ} \mathrm{C}$. there was no appreciable difference whether they were in the air or in nitrogen. The tempera- 
[Vol. 19.

ture of the bath in the present experiments was 25.4 and $25.5^{\circ} \mathrm{C}$. It seems improbable that the difference in behavior in the two sets of experiments could be due to a difference in temperature of only $4.5^{\circ} \mathrm{C}$. Richards' experiments were conducted with material that had been sent from Tucson to New York and consequently it was not fresh, but the writer's material was taken from the plants only as it was to be used. In one of Richards' tables he gives the time as April I-3, about two and a half months later in the season than the experiments here reported. At Tucson these months are very important as far as plant activity is concerned. In early January nearly every plant is dormant, while in late March everything is in full growth. Whether these differences in condition of the plants are significant or not is very hard to state. They may, however, account for the very great differences in results obtained. Richards continued his experiments for only a few hours. In the two experiments here reported the plants were exposed to nitrogen for 96 and 138 hours.

Experiment 36 and its control are illustrated by text figure 7 . About I5 joints weighing 250 grams were used in this experiment. No determination of $\mathrm{CO}_{2}$ after nitrogen was introduced was made until the following day because it had been found that several hours were required completely to remove oxygen from the respiration chamber. It will be noticed that for at least 40 hours after nitrogen was introduced the respiration was higher than before its introduction. During the following day the rate fell below the initial as well as below the control, which in this experiment remained fairly constant. At the end of 138 hours of exposure to the nitrogen atmosphere the respiration was still 54 percent of the original. This shows a remarkable ability to respire anaerobically. At the completion of the experiment only a few joints showed a few small grayish-green spots. Two weeks later those in soil were all in healthy condition with one exception. Those on the laboratory table showed slight browning in one specimen. These plants were thus injured only to a very slight degree.

In the second experiment, which lasted only 96 hours, the rate fell quite rapidly in the control plants as well as in the experimental plants. The experimental plants were considerably injured at the end of the experiment and after 3 weeks in the soil they were all dead. The plants evidently were not in as good condition as in experiment 36 , which was started 9 days later with material from the same plant. In experiment $3^{6}$ all but two or three joints were plump and large in diameter, whereas in the first experiment most joints were slender. The slender joints were more injured in both experiments than the plump ones. The writer does not know whether the slender ones were younger than the plump ones or not.

\section{OPUNTIA ENGELMANNII}

Opuntia engelmannii is one of the flat-jointed cacti with joints not over three-quarters of an inch thick, which are so strongly attached to the rest of 
the plant that removal necessitates cutting, but of course the cut surface is very small. The material for the two experiments in which this species was used was obtained from two individuals, one for each experiment. The joints were the youngest ones on a branch.

Text figure 8 represents experiment 37 and its control. This experiment was conducted at the same time as experiment 36 so that the experimental conditions were identical. Of the whole group of experiments it is the most astonishing because at no time during the $\mathrm{I} 3^{8}$ hours that the plants were in nitrogen was the $\mathrm{CO}_{2}$ production less than when they were in air at the be-

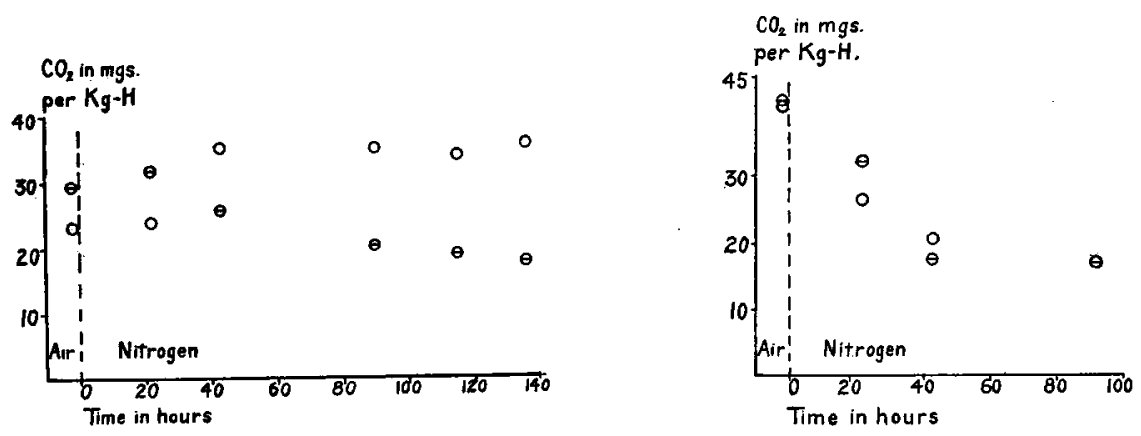

Text Figs. 8 and 9. Fig. 8 (left). Respiration of Opuntia engelmannii joints. Four joints were used in each jar. FIG. 9 (right). Respiration of Echinocereus fendleri plants. Five plants were used in each respiration chamber.

ginning of the experiment. It will be noted that though the $\mathrm{CO}_{2}$ production decreased in the control day by day the experimental plants maintained practically the same rate from the second to the sixth day. At the end of the experiment and several weeks later no difference could be detected either externally or internally between those plants that had been in nitrogen and those that had been in air.

In the other experiment there was a fall in respiration below the initial after two days but the decrease was not as great as that in the control. Here also the plants were in perfect condition several weeks after they were taken out of the respiration chamber.

Here is a plant which is relatfvely thin, has an abundance of stomata, and should be abundantly supplied with air, and which one would expect to suffer quickly from lack of oxygen, yet it respires faster in absence of oxygen than in its presence, without injury to the plant tissue from the products of this incomplete respiratory process.

\section{ECHINOCERFUS FENDLERI}

Echinocereus fendleri is a cactus that grows in clusters of a dozen or more heads, which all come from one root by budding near the soil level. The plants are two to three inches in diameter and may grow as tall as ten inches. 
For the experiments single plants were used either without buds or with very small buds. These plants were therefore rather young.

Two experiments, each with a control, were performed with this species. In one experiment air was reintroduced after 72 hours in nitrogen. The rate of $\mathrm{CO}_{2}$ production increased gradually during the 3 days that the plants were in air, until the time nitrogen was reintroduced, when the respiration was 130 percent higher than it was just preceding the air introduction. When nitrogen was reintroduced the $\mathrm{CO}_{2}$ production fell very abruptly to about the level at which it had been 4 days before when also in nitrogen. At the end of the experiment, 190 hours after the first introduction of nitrogen, the experimental plants respired as much as the control plants. At the beginning of the experiment they respired somewhat more. At the end of the experiment the plants that had been in the nitrogen had a few small yellow spots on the surface, but sectioning showed that these were only in the surface, where chlorophyll had been injured. The interior was apparently normal.

In the second experiment with Echinocereus fendleri, which is illustrated by text figure 9,5 plants were used in each container. As will be noticed from the graph the experimental and control plants respired practically the same at the beginning of the experiment and at the end they were identical. In between, the control was higher one day and the experimental plants the next day. If a curve were drawn through the points the two would be very nearly the same. When the plants were taken out of the jar at the completion of the experiment one showed some spots that were slightly paler green than normal, but the others were not different in appearance from the control plants.

From these two experiments it is thus evident that Echinocereus fendleri is able to respire in the absence of air as readily as in air, without any or with very slight superficial injury. No injury deeper than a few millimeters was ever noticed.

\section{Leaves from Thin-leaved Plants}

To determine whether other desert plants than cacti would behave in the same way as the plants investigated, the respiration of the leaves and young shoots of two perennials which had developed during December was also measured. The species were Verbena ciliata and Encelia farinosa, the leaves of which are of medium thickness, rather hairy in both plants.

The experiment with leaves of Encelia farinosa (text fig. Io) shows that 50 hours after nitrogen was introduced the respiration was only I7 percent of what it had been before. The leaves in air still respired 77 percent as much as they did at the beginning. The leaves of Verbena ciliata showed even a greater difference between those in nitrogen and those in air. These experiments on leaves leave no doubt as to the difference between the succulent cacti and non-fleshy plant structures. At the end of the experiment the leaves which had been in nitrogen were turning black and dried much sooner than the control leaves, when left on the laboratory table. These leaves were in to- 
tal absence of oxygen not more than $4 \mathrm{I}$ hours at the most, as the gas passing through the bottle showed the presence of oxygen as late as $4 \mathrm{I}$ hours before the experiment was ended. In this experiment as in others the presence of oxygen was detected by passing the gas through a tube containing phosphorus. The presence of oxygen was readily detected by the formation of white phosphorus pentoxid.

These experiments show very conclusively that the succulent cactus plants are capable of existing in an atmosphere free of oxygen for several days with-

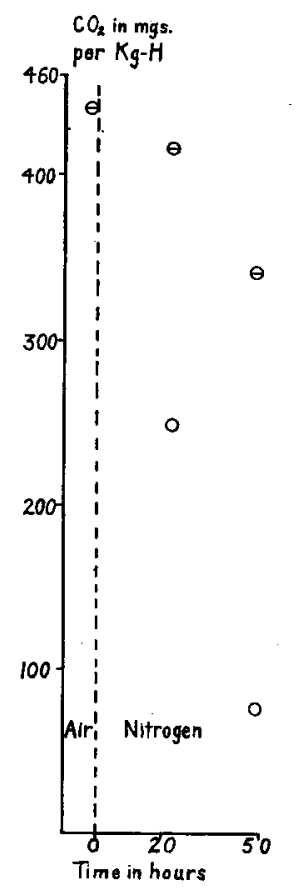

TExT FIG. 10. Respiration of leaves and young shoots from Encelia farinosa plants. The leaves were not over two months old and many much younger.

out any injury beyond a few millimeters at the surface, and that most of the plants are not injured in the least. To this statement must be made the exception of two small plants of Neomammillaria microcarpa and the slender joints of Opuntia versicolor. In nitrogen they respired either more than the control, as in Opuntia engelmannii, or about the same as the control. From these experiments it is of course impossible to make any statement concerning the type of respiration which takes place under normal conditions. However, when one compares the injury produced in the thin leaves, caused by a very short period of anaerobiosis, with that in the cacti produced during a much longer period of oxygen absence, one is forced to believe that the interior of the cacti is accustomed to the products of anaerobic respiration. Spoehr (3) 
has shown that in air Opuntia versicolor produces some alcohol, though of course much more alcohol is formed in the absence of oxygen. Further experiments must be conducted to test the assumption that anaerobic respiration takes place normally in the interior of cacti.

\section{SuMMARY}

I. It has been shown that the cacti Carnegiea gigantea, Ferocactus zeislizeni, Neomammillaria microcarpa, Echinocereus fendleri, Opuntia engelmanii, and $O$. versicolor are capable of producing as much or nearly as much $\mathrm{CO}_{2}$ in absence of oxygen as they do in air. This is not true of the thin leaves of the desert perennials Encelia farinosa and Verbena ciliata.

2. When kept under anaerobic conditions for several days most of the cactus plants were not injured. Some were injured slightly in the surface layers, and one lot of Opuntia versicolor and two small specimens of Neomammillaria microcarpa were so badly injured that they later died.

3. Like tomato fruits, cacti showed a large increase in $\mathrm{CO}_{2}$ production when air was introduced after the plants had been in nitrogen for some time.

The writer takes this opportunity to express his appreciation of the facilities extended him by the Carnegie Institution of Washington. He wishes especially to thank Dr. Shreve, the Director of the Desert Laboratory at Tucson, Arizona, for his thoughtfulness in supplying apparatus and material.

Department of Botany,

UNIVERSITY OF MichIGAN, AnN ARbor, Michigan

\section{LITERATURE CITED}

I. Gustafson, F. G. Intramolecular respiration of tomato fruits. Amer. Jour. Bot. I7: $101 \mathrm{I}, 1930$.

2. Richards, H. M. Acidity and gas interchange in cacti. Carnegie Institution Washington Pub1. 209. 1915.

3. Spoehr, H. A. The carbohydrate economy of cacti. Carnegie Institution Washington Publ. 287. 1919. 